\title{
Biased Technical Change and Capital-Labour Substitution in Finland, 1902-2003
}

\author{
Jukka Jalava \\ Statistics Finland and Helsinki School of Economics \\ Matti Pohjola \\ Helsinki School of Economics and HECER \\ Antti Ripatti \\ Bank of Finland \\ and \\ Jouko Vilmunen \\ Bank of Finland
}

Discussion Paper No. 56

March 2005

ISSN 1795-0562

HECER - Helsinki Center of Economic Research, P.O. Box 17 (Arkadiankatu 7), FI-00014 University of Helsinki, FINLAND, Tel +358-9-191-28780, Fax +358-9-191-28781, E-mail info-hecer@helsinki.fi, Internet www.hecer.fi 


\title{
Biased Technical Change and Capital-Labour Substitution in Finland, 1902-2003*
}

\begin{abstract}
The paper argues that a Cobb-Douglas specification of the Finnish aggregate production function cannot be rejected if a sufficiently long enough time period (100 years) is considered. It is, however, a misleading description of the production technology for shorter (3-5 decades) periods. Controlling for biased technical change, the elasticity of substitution is significantly below one, in the range 0.4-0.5 during 1945-2003. Given that similar results have been obtained for the US economy, the analysis shows that the value of the elasticity of substitution cannot be dependent on some specific structure of economic institutions but is likely to reflect more general aspects of technology and production.
\end{abstract}

JEL Classification: O3, O4

Keywords: capital-labour substitution, elasticity of substitution, technical change

Jukka Jalava

Economic Statistics

$6 \mathrm{C}$

FI-00022 Statistics Finland

FINLAND

e-mail: jukka.jalava@stat.fi

Antti Ripatti

Bank of Finland

P.O. Box 1610

FI-00101 Helsinki

FINLAND

e-mail: antti.ripatti@bof.fi
Matti Pohjola

Helsinki School of Economics

P.O. Box 1210

FI-00101 Helsinki

FINLAND

e-mail: matti.pohjola@hse.fi

Jouko Vilmunen

Bank of Finland

P.O. Box 1610

FI-00101 Helsinki

FINLAND

e-mail: jouko.vilmunen@bof.fi

* The opinions expressed here are those of the authors and do not necessarily reflect the views of Statistics Finland or the Bank of Finland. Jukka Jalava's research is partly supported by the EU KLEMS project "Productivity in the European Union: A Comparative Industry Approach", funded by the European Commission, Research Directorate General as part of the 6th Framework Programme, Priority 8, "Policy Support and Anticipating Scientific and Technological Needs". Matti Pohjola gratefully acknowledges financial support from the Yrjö Jahnsson Foundation. 


\section{Introduction}

The steady-state growth theorem states that, if a neoclassical growth model is to possess a steady state with positive growth and positive capital share, then either the elasticity of substitution between capital and labour must be equal to one or technical change must be labour augmenting (Uzawa 1961, Jones 2004). Empirical findings suggest that steadystate growth is possible. For example, the growth rate of GDP per capita does not show any specific trend for the past 125 years in the United States.

The puzzle is that there is not much empirical support for the other parts of the theorem. Although the income shares of capital and labour show no trends in the long run, they are not constant over time, implying that the elasticity of substitution cannot be equal to one. Many econometric analyses find it to be less than one (see, e.g., David and Van de Klundert 1965, Antràs 2004). Empirical evidence also indicates that labour-augmenting technical change is not a uniform pattern of development across all countries and all periods (Marquetti 2003). The ongoing decline in the relative prices of new capital goods, such as computers and semiconductors, can be taken as current evidence for capital-augmenting technical change.

These apparent inconsistencies have awakened economists' interest in both the theoretical and empirical analysis of the direction of technical change and the shape of the aggregate production function. In the spirit of Samuelson (1965), Acemoglu (2003) has developed a theoretical model in which profit-maximizing firms choose the direction of technical change. The fact that capital can be accumulated while labour cannot implies that all technical change is labour-augmenting along the balanced growth path. However, along the transition path there is typically capital-augmenting technical change. The factor shares are constant in the long run but can change in the short run.

Jones (2004) has presented a new, idea-based production function whose shape is governed by the distribution of ideas. It exhibits a local elasticity of substitution between capital and labour that is less than one but a global elasticity that is equal to one. Production techniques are ideas that get discovered over time. They indicate how to produce with a particular amount of capital per labour. A particular technique is thus appropriate at a given mix of inputs and can be described by a local production function in which the elasticity of substitution is less than one. If the capital-labour ratio is increased, diminishing returns set in quickly and the capital share declines. New techniques are needed if firms want to produce with substantially higher capital-labour ratios. Thus, new ideas, that are appropriate at the new input mix, must be discovered. The global elasticity of substitution is therefore governed by the distribution of ideas. Jones has proved that if the distributions related to ideas are Pareto distributions, then the global elasticity of substitution equals one and technical change is labour augmenting in the long run.

On the empirical side of the issue, Antràs (2004) has shown in the spirit of David and Van de Klundert (1965) that the US economy is not well described by an aggregate production function that assumes the elasticity of substitution to be equal to one. The new 
estimates suggest that, controlling for the biased technical change, the elasticity is likely to be considerably below one, and may even be lower than 0.5 .

Caselli and Coleman (2004) as well as Caselli (2005) have demonstrated that the explanation to the observed large income differences between countries depends critically on what is assumed about the elasticity of substitution and about the direction of technical change. If technology is non-neutral and the elasticity low enough, then differences in factor endowments between countries can explain most of the measured cross-country variation in income per capita. But when the elasticity is close to one, then the efficiency with which factors are used plays a more important role in the explanation, and as much as 50 per cent of income differences can be attributed to differences in efficiency.

Our aim in this paper is to contribute to this ongoing debate by estimating the aggregate production function of the Finnish economy. Finland is an interesting test case because its growth rate of GDP per capita was the highest in Europe in the $20^{\text {th }}$ century. During this period it developed from a relatively backward agricultural society to a modern Nordic welfare state. The advancement in prosperity was initially based on the successful utilization of its natural resources by the forest and basic metal industries in the wake of the second industrial revolution. Later in the 1990s, the information and communication technology sector became the leading industry in terms of the contribution to labour productivity and GDP growth. According to the World Economic Forum (2004), Finland is the most competitive country in the world. Be that as it may, Finland must, however, be one of those countries that had to adjust its input mixes of capital and labour rapidly to fit existing production techniques as well as to develop new ideas that are appropriate for new input mixes.

The next section introduces the CES production function to be estimated and the method of estimation. The data and estimation results for the period 1902-2003 are presented in section 3. Section 4 concludes.

\section{Model specification}

Let us assume that aggregate output $Y_{t}$ in period $t$ can be represented as the following CES function of capital $K_{t}$ and labour $L_{t}$ :

$$
Y_{t}=\left[\delta\left(A_{t} K_{t}\right)^{-\rho}+(1-\delta)\left(B_{t} L_{t}\right)^{-\rho}\right]^{-1 / \rho}
$$

Here $\rho$ is a substitution parameter, $\delta$ a distribution parameter between 0 and $1, A$ an index of capital-augmenting technical change and $B$ an index of labour-augmenting technical change. If factors are paid their marginal products, then the share of payments to capital in total output is

$$
s_{t}^{K}=\frac{\delta\left(A_{t} K_{t}\right)^{-\rho}}{\delta\left(A_{t} K_{t}\right)^{-\rho}+(1-\delta)\left(B_{t} L_{t}\right)^{-\rho}}=\delta A_{t}^{(\sigma-1) / \sigma}\left(\frac{Y_{t}}{K_{t}}\right)^{(1-\sigma) / \sigma} .
$$


As the first equality shows, the income share of each production factor depends on the rate of bias of technical change as well as on the elasticity of substitution between capital and labour $\sigma=1 /(1+\rho)$ which is non-negative when $\rho \geq-1$. The second equality demonstrates that, given the level of $A_{t}$, there is a one-for-one relationship between the capital share and the capital-output ratio. An improvement in capital productivity $(Y / K)$ increases the capital share when the elasticity of substitution is less than one. Therefore, it should be no surprise to have both time series display increasing trends over short periods of time, like the 1990s in Finland, if the elasticity of substitution is less than one in the short run.

By writing the relative factor share as

$$
\frac{s_{t}^{L}}{s_{t}^{K}}=\frac{1-\delta}{\delta}\left(\frac{K_{t} / L_{t}}{B_{t} / A_{t}}\right)^{(1-\sigma) / \sigma}
$$

we can see that, if $\sigma$ is less than one, an increase in the capital-labour ratio $K / L$ tends to reduce the income share of capital. Sufficiently fast labour-augmenting technical change can however cause the capital share to move in the opposite direction. Consequently, if $K / L$ and $B / A$ growth is at the same rate, constant factor shares can also be consistent with aggregate production functions with non-unit elasticities of substitution.

The standard way of estimating the parameters of the production function (1) is to apply the first-order conditions of profit maximization by firms in a competitive framework (for a review, see Antràs 2004). The one for capital implies that its marginal product equals its real price:

$$
\frac{\partial Y_{t}}{\partial K_{t}}=\delta A_{t}\left(\frac{Y_{t}}{A_{t} L_{t}}\right)^{\frac{1}{\sigma}}=\frac{r_{t}}{p_{t}} .
$$

Here $r$ is the price of capital services and $p$ the price of output. Assuming now that capital-augmenting technical change takes place over the course of time at the constant rate $\alpha$, this can be written as

$$
\ln \left(\frac{Y_{t}}{K_{t}}\right)=\gamma_{1}+\sigma \ln \left(\frac{r_{t}}{p_{t}}\right)+\alpha(1-\sigma) t,
$$

where $\gamma_{1}$ is a constant.

Denoting the wage rate by $w$, the first-order condition for labour is 


$$
\frac{\partial Y_{t}}{\partial L_{t}}=(1-\delta) B_{t}\left(\frac{Y_{t}}{B_{t} L_{t}}\right)^{\frac{1}{\sigma}}=\frac{w_{t}}{p_{t}}
$$

Assuming that technical change augments labour at a constant rate $\beta$, the following estimable equation is obtained:

$$
\ln \left(\frac{Y_{t}}{L_{t}}\right)=\gamma_{2}+\sigma \ln \left(\frac{w_{t}}{p_{t}}\right)+\beta(1-\sigma) t,
$$

$\gamma_{2}$ being a constant.

Equations (5) and (7) can be manipulated to obtain the third estimable equation as

$$
\ln \left(\frac{K_{t}}{L_{t}}\right)=\gamma_{3}+\sigma \ln \left(\frac{w_{t}}{r_{t}}\right)+(\beta-\alpha)(1-\sigma) t
$$

where again $\gamma_{3}$ is a constant. This can be used to estimate the bias $\beta$ - $\alpha$ in technical change as well as the elasticity of substitution $\sigma$.

This can also be estimated in the form

$$
\ln \left(\frac{K_{t}}{L_{t}}\right)=\gamma_{4}+\frac{\sigma}{1-\sigma} \ln \left(\frac{s_{t}^{L}}{s_{t}^{K}}\right)+(\beta-\alpha) t
$$

which is obtained from equation (3) by taking logs. This is our fourth estimable equation.

Controlling for a possible bias in technical change is important in the estimation. If we assume that $A$ and $B$ grow at the same rates, then equation (3) implies that $\sigma=1$ in such an economy where the capital-labour ratio grows over time but the factor shares stay approximately constant. Consequently, such a misspecification of the estimation equation biases the estimates towards finding results that support the Cobb-Douglas production function (Antràs 2004).

\section{Data and estimation results}

The production function is estimated for the non-residential market sector of the Finnish economy. The output measure is gross domestic product at basic prices, the year 2000 being the base year for the volume series. Finnish National Accounts data are used for the period 1960-2003. Information for the earlier years is from Hjerppe (1988). Labour hours and investment data come from the same sources. 
The flow of capital services is assumed to be proportional to the aggregate capital stock. Capital stocks were first obtained for seven types of assets using the perpetual inventory method with geometric depreciation profiles. Using their asset prices as weights, the stocks were then aggregated into a volume index of capital services. The rental price of capital was computed as the ratio of nominal capital income to the real capital stock.

Labour remuneration data contain wages, salaries and employers' social security contributions and come from the Finnish National Accounts for the period 1960-2003 and from Tiainen (1994) for the earlier years. The wages for the self-employed were imputed on the basis of the average wage.

Figure 1 displays the data. It reveals the rapid growth of labour productivity $Y / L$ from the late 1940 s to the early 1970 s as well as the decline in its growth thereafter. The relative price of labour $w / r$ is also seen to increase and the capital intensity $K / L$ to rise until the early 1990s when the depression hit the economy. In the 1990s, the real price of capital $r / p$ rose, the capital intensity stopped growing and the output-capital ratio $Y / K$ improved.

Figure 1. The time series data (logarithmic indexes, $1900=\ln (100))$

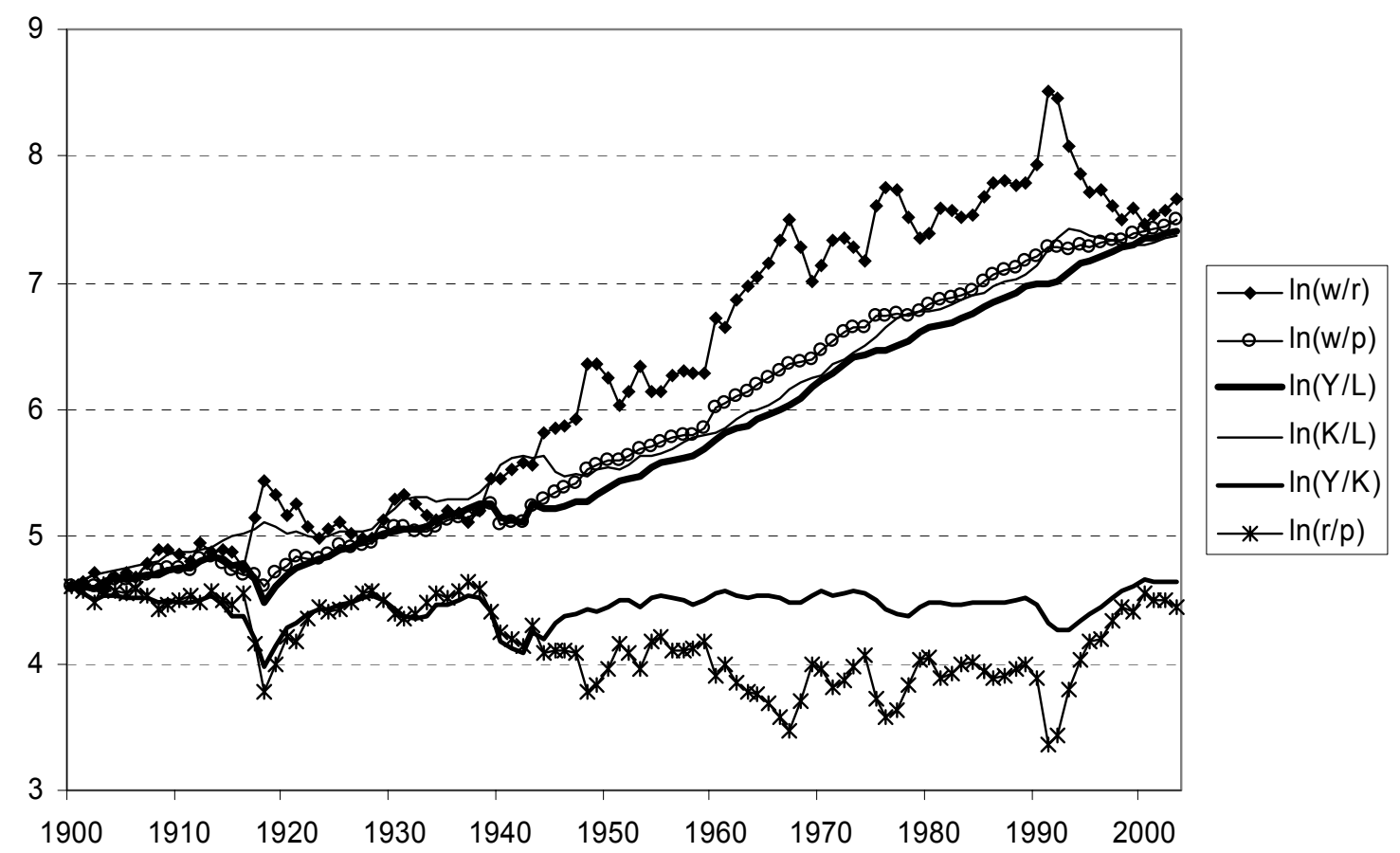

The elasticity of substitution $\sigma$ and the rates of the factor-augmenting technical changes $\alpha$ and $\beta$ are estimated using equations (5), (7), (8) and (9) by assuming that they hold only in the long-run. Short-run deviations may arise, for example, from the costs of adjusting inputs and from the fluctuations of factor-augmenting technical changes around their long-run trends. In addition, for the purpose of econometric modeling and statistical 
inference, we assume that the log-levels $\ln (Y / K), \ln (r / p), \ln (Y / L), \ln (w / p), \ln (K / L), \ln (w / r)$ and $\ln \left(s^{L} / s^{K}\right)$ are generated by unit root processes, i.e. they are integrated of order one. Under this assumption we may use cointegration methods to estimate the parameters of interest. We apply Johansen's (1995) approach, which is based on the following cointegrated $\operatorname{VAR}(p)$ model

$$
\Delta x_{t}=\sum_{i=1}^{p-1} \Psi_{i} \Delta x_{t-i}+\varphi \gamma^{\prime}\left[\begin{array}{ll}
x_{t-1} & t
\end{array}\right]^{\prime}+\mu+\varepsilon_{t}, \quad \varepsilon_{t} \sim N I D(0, \Sigma),
$$

where $\Psi_{i}(i=1, \ldots, p-1)$ and $\varphi$ are matrices of short-run parameters and $x_{t}$ and $\gamma$ are as defined in Table 1. Note that by construction we restrict the deterministic linear timetrend to lie only in the cointegration space.

Table 1. Definition of variables and parameter matrices

\begin{tabular}{cccc}
\hline Equation & $x_{t}$ & $\gamma$ \\
\hline$(5)$ & {$[\ln (Y / K)$} & $\ln (r / p)]^{\prime}$ & {$\left[\begin{array}{lll}-1 & \sigma & \alpha(1-\sigma)\end{array}\right]^{\prime}$} \\
$(7)$ & {$[\ln (Y / L)$} & $\ln (w / p)]^{\prime}$ & {$\left[\begin{array}{llll}-1 & \sigma & \beta(1-\sigma)\end{array}\right]^{\prime}$} \\
$(8)$ & {$[\ln (K / L)$} & $\ln (w / r)]^{\prime}$ & {$\left[\begin{array}{ccc}-1 & \sigma & (\beta-\alpha)(1-\sigma)\end{array}\right]^{\prime}$} \\
$(9)$ & {$[\ln (K / L)$} & $\left.\ln \left(s^{L} / s^{K}\right)\right]^{\prime}$ & {$\left[\begin{array}{lll}-1 & \sigma /(1-\sigma) & (\beta-\alpha)\end{array}\right]^{\prime}$} \\
\hline
\end{tabular}

The estimation results are presented in table 2. The lag-length choice, $p=2$, of VAR results non-autocorrelated residuals. The first two columns relate to Johansen's trace test of the cointegration rank, ${ }^{1}$ which in the present context specifically tests for the lack of cointegration between the component variables of vector $x_{t}$. The test is a joint test of the validity of the CES production function and the constant growth rate of factoraugmenting technical change. Therefore, if no cointegration is found, it may well be due to a poor approximation of technological trend as a deterministic linear time trend and not necessarily due to the invalidity of the CES production function. Testing the null of no cointegration is not entirely satisfactory since we would instead prefer to test for the nonrejection of the null of cointegration rank one. The cointegration test statistic suffers from poor small-sample properties. Those sub-samples that cover only two to three decades are rather small for reliable statistical inference.

The third column reports the estimated elasticity of technical substitution $\sigma$ assuming that the cointegration rank equals one, i.e., that the production function is CES and the factor-augmenting technical change can be approximated by a deterministic linear time trend. The standard error is given in the fourth column. The slope of the time trend in factor-augmenting technical change is expressed in the next column. The last two columns relate to the joint term of the trend slope and the elasticity of substitution and its standard error.

\footnotetext{
${ }^{1}$ The computations were done with the PcGive 10.3.
} 
Table 2. Estimation results

\begin{tabular}{|c|c|c|c|c|c|c|c|}
\hline \multicolumn{8}{|c|}{ Capital demand equation (5) } \\
\hline & $\begin{array}{r}\text { Cointe- } \\
\text { gration } \\
\text { rank }\end{array}$ & $\begin{array}{l}p \text {-value of } \\
\text { no cointe- } \\
\text { gration }\end{array}$ & $\sigma$ & std.err & $\alpha$ & $\alpha(1-\sigma)$ & std.err \\
\hline $1902-2003$ & 0 & 0.113 & -0.16 & 0.130 & 0.0003 & 0.0004 & 0.00137 \\
\hline $1902-1939$ & 1 & 0.007 & 0.78 & 0.047 & -0.0054 & -0.0012 & 0.00069 \\
\hline $1945-2003$ & 1 & 0.001 & 0.42 & 0.092 & -0.0036 & -0.0021 & 0.00114 \\
\hline 1945-1974 & 1 & 0.003 & 0.08 & 0.066 & 0.0049 & 0.0045 & 0.00139 \\
\hline $1975-2003$ & 0 & 0.052 & 0.66 & 0.065 & -0.0246 & -0.0085 & 0.00167 \\
\hline \multicolumn{8}{|c|}{ Labour demand equation (7) } \\
\hline & $\begin{array}{l}\text { Cointe- } \\
\text { gration } \\
\text { rank }\end{array}$ & $\begin{array}{l}p \text {-value of } \\
\text { no cointe- } \\
\text { gration }\end{array}$ & $\sigma$ & std.err & $\beta$ & $\beta(1-\sigma)$ & std.err \\
\hline $1902-2003$ & 1 & 0.079 & 0.83 & 0.123 & 0.0272 & 0.0046 & 0.00400 \\
\hline 1902-1939 & 1 & 0.004 & 1.46 & 0.090 & 0.0130 & -0.0060 & 0.00141 \\
\hline $1945-2003$ & 0 & 0.182 & 0.50 & 0.106 & 0.0407 & 0.0203 & 0.00417 \\
\hline 1945-1974 & 0 & 0.675 & 1.26 & 0.413 & 0.0513 & -0.0132 & 0.01895 \\
\hline $1975-2003$ & 0 & 0.200 & 0.08 & 0.087 & 0.0361 & 0.0333 & 0.00260 \\
\hline \multicolumn{8}{|c|}{ Capital intensity equation (8) } \\
\hline & $\begin{array}{l}\text { Cointe- } \\
\text { gration } \\
\text { rank }\end{array}$ & $\begin{array}{l}p \text {-value of } \\
\text { no cointe- } \\
\text { gration }\end{array}$ & $\sigma$ & std.err & $(\beta-\alpha)$ & $(\beta-\alpha)(1-\sigma)$ & std.err \\
\hline $1902-2003$ & 0 & 0.692 & -2.42 & 0.913 & 0.0340 & 0.1164 & 0.03557 \\
\hline $1902-1939$ & 0 & 0.031 & -8.52 & 1.893 & 0.0176 & 0.1677 & 0.03579 \\
\hline $1945-2003$ & 1 & 0.000 & 0.44 & 0.064 & 0.0432 & 0.0240 & 0.00244 \\
\hline 1945-1974 & 1 & 0.000 & 0.09 & 0.072 & 0.0416 & 0.0378 & 0.00443 \\
\hline $1975-2003$ & 1 & 0.004 & 0.52 & 0.037 & 0.0499 & 0.0242 & 0.00114 \\
\hline \multicolumn{8}{|c|}{ Capital intensity equation (9) } \\
\hline & $\begin{array}{l}\text { Cointe- } \\
\text { gration } \\
\text { rank }\end{array}$ & $\begin{array}{l}p \text {-value of } \\
\text { no cointe- } \\
\text { gration }\end{array}$ & $\sigma$ & $\sigma /(1-\sigma)$ & Std.err. & $(\beta-\alpha)$ & Std.err. \\
\hline $1902-2003$ & 0 & 0.652 & -3.22 & -0.763 & 0.274 & 0.0349 & 0.0038 \\
\hline 1902-1939 & 1 & 0.032 & -3.68 & -0.786 & 0.208 & 0.0177 & 0.0021 \\
\hline $1945-2003$ & 1 & 0.000 & 0.43 & 0.769 & 0.126 & 0.0421 & 0.0015 \\
\hline 1945-1974 & 1 & 0.000 & 0.09 & 0.097 & 0.079 & 0.0417 & 0.00252 \\
\hline $1975-2003$ & 1 & 0.001 & 0.49 & 0.970 & 0.09 & 0.0471 & 0.00188 \\
\hline
\end{tabular}

The results for equation (5), based on the first-order condition with respect to capital, show that the null hypothesis of no cointegration is not rejected for the full sample but is rejected for all the sub-samples. The estimated elasticity of substitution is implausibly small (negative) in the full sample. In the sub-samples, its value varies across periods but is always significantly below one, meaning that the Cobb-Douglas specification is 
rejected. The point estimates vary from 0.8 in the pre-war period to 0.1 in $1945-1974$. The slope of the trend in the capital-augmenting technical change is negative, and significantly different from zero in all the sub-periods except in 1945-1974.

A different set of conclusions on the existence of cointegration as well as on the size of the elasticity of substitution emerges when we use the first-order condition with respect to labour input, i.e. equation (7), in our tests. Assuming that the cointegration rank is one in the full sample gives us a point estimate of 0.8 for the elasticity. We cannot, however, reject Cobb-Douglas in this case. For the pre-war period the estimated elasticity actually exceeds unity. In the post-war sub-periods the null hypothesis of no cointegration cannot be rejected under any conventional significance levels. This contradicts the results obtained from equation (5). Since specification (5) performs well in that period, this suggests that the linear trend is a poor approximation of labour-augmenting technical change in the period after 1945.

The combination of the two first-order conditions, i.e. equation (8), gives us a similar picture as equation (5) for the period 1945-2003. This conclusion also comes out from equation (9) in which the ratio between labour and capital shares is used instead of the relative price of labour and capital. Interestingly the difference between the slope of labour and capital augmenting technical change increases significantly towards the end of the sample period.

To summarize, there is some evidence in the data to support the view that the value of the elasticity of substitution can be close to one in the long run. This comes in the form that we cannot reject the null hypothesis of no cointegration and the Cobb-Douglas specification in the estimation of equation (7) for the period 1902-2003. In all those subsample estimations in which the null hypothesis cannot be rejected, the elasticity of substitution is lower than one in the periods after 1945. This holds for all specifications of the estimable equation. The elasticity lies in the range $0.4-0.5$ in the estimations for the years 1945-2003.

\section{Conclusions}

This paper has argued that a Cobb-Douglas specification of the Finnish aggregate production function cannot be rejected if a sufficiently long enough time period (100 years) is considered. It is, however, a misleading description of the production technology for shorter (3-5 decades) periods. Controlling for biased technical change, the elasticity of substitution is significantly below one, in the range 0.4-0.5, during 19452003. The result is consistent with our earlier findings obtained for shorter periods and based on somewhat different approaches (Pohjola 1996, Ripatti and Vilmunen 2001).

Using a similar approach, Antràs (2004) found that the elasticity of substitution is likely to be considerably below one, and may even be lower than 0.5 , in the private sector of the US economy in the period 1948-1998. Given that the Finnish and the US economies are quite different from each other, the results show that the value of the elasticity of substitution cannot be dependent on some specific structure of economic institutions but 
is likely to reflect more general aspects of technology and production. This finding gives support to recent theoretical work that is re-examining the sources of economic growth.

\section{References}

Acemoglu, D. (2003), Labor- and capital-augmenting technical change, Journal of European Economic Association 1: 1-37.

Antràs, P. (2004), Is the U.S. aggregate production function Cobb-Douglas? New estimates of the elasticity of substitution, Contributions to Macroeconomics 4:1.

Caselli, F. (2005), Accounting for cross-country income differences, CEP Discussion Paper No 667, London School of Economics.

Caselli, F. and W.J. Coleman (2004), The world technology frontier, working paper, Harvard University.

David, P. A. and Th. Van de Klundert (1965), Biased efficiency and capital-labor substitution in the U.S., 1899-1960, American economic Review 55: 357-394.

Hjerppe, R. (1988), Suomen talous 1860-1985, kasvu ja rakennemuutos (The Finnish Economy 1860-1985. Growth and Structural Change), Studies on Finland's Economic Growth XIII, Bank of Finland Publications Helsinki.

Johansen, S. (1995) Likelihood-Based Inference in Cointegrated Vector Autoregressive Models, Oxford, Oxford University Press.

Jones, C. I. (2004), The shape of production functions and the direction of technical change, unpublished paper, University of California, Berkeley.

Marquetti, A.A. (2003), Analyzing historical and regional patterns of technical change from a classical-Marxian perspective, Journal of Economic Behavior and Organization 52: 191-200.

Pohjola, M. (1996), Tehoton pääoma (Inefficient Capital), WSOY, Porvoo.

Ripatti, A. and J. Vilmunen (2001), Declining labour share: Evidence of a change in the underlying production technology?, Bank of Finland Discussion Paper 10/2001.

Samuelson, P.A. (1965), A theory of induced innovation along Kennedy-Weisäcker lines, Review of Economics and Statistics 47: 343-356. 
Tiainen, P. (1994), Taloudellisen kasvun tekijät Suomessa. Työvoiman, pääoman ja kokonaistuottavuuden osuus vuosina 1900-90 (Sources of Growth in Finland. Contribution of Labour Force, Capital and Total Productivity in the Years 190090, in Finnish with English Summary and Tables), Helsinki.

Uzawa, H. (1961), Neutral inventions and the stability of growth equilibrium, Review of Economic Studies 28: 117-124.

World Economic Forum (2004), Global Competitiveness Report 2003-2004. 